\title{
Gender, feminism and food studies
}

\author{
Desiree Lewis
}

\begin{abstract}
Policy research and scholarship on food has rapidly increased in recent decades. The attention to 'gender' within this work appears to signal important practical and academic efforts to mainstream gendered understandings of food consumption, distribution and production into expansive conceptualisations of human security. This article argues that the gender-related work on food has wide-ranging and often troubling political and theoretical foundations and implications. Often growing out of knowledge regimes for managing social crises and advancing neo-liberal solutions, much gender and food security work provides limited interventions into mainstream gender-blind work on the nexus of power struggles, food resources and globalisation. A careful analysis of knowledge production about gender and food is therefore crucial to under- standing how and why feminist food studies often transcends and challenges dominant forms of scholarship and research on food security. This article's critical assessment of what food security studies in South Africa has entailed at the regional level and in global terms also focuses on the methodological and theoretical feminist interventions that can stimulate rigorous conceptual, research and practical attention to what has come to be understood as food sovereignty.
\end{abstract}

\section{Introduction}

Policy research, development practice and academic scholarship on food security have mushroomed in recent years. Within this body of research and development practice, work focusing specifically on the gendered dimensions of food systems has also steadily escalated. This article addresses the need to both disaggregate and interrogate the ideological, political, intellectual and, indeed, practical consequences of strands within this work. While this may lay the article open to the charge of 'too much talk about ideas and not enough talk about or for action', I implicitly present a case for thoroughly scrutinising our current industries of development-oriented research and traditions of knowledge, especially when these lay strong claims to engaging pressing social concerns.

Deconstructing which knowledge traditions matter and become dominant and what these traditions yield, as well as which forms of knowledge-making are marginalised and why, is a crucial heuristic practice in an age when much knowledge and information is packaged in rigidly instrumentalist ways. Frequently reduced to 'data' or processed as digestible sound bites, 'knowledge' - disconnected from its roots in political and ideological agendas - is 
often reconfigured as directly useful information that can be quickly registered, hastily applied, and immediately forgotten. In these circuits of applied information, true socially engaged knowledge and research with the potential to drive long-term and sustainable practice is ultimately jettisoned.

Like human security, food security is a field of research and practice that easily attracts such circuits of information: paradigms and research methods that are galvanised with the aim of urgently responding to social crises, yet which offer very little when scrutinised closely or when applied to the considerable development challenges of marginalised communities or groups. Food security research is therefore an arena where thoughtful attention to the discursive legacies of particular research approaches is especially significant - both in furthering rigorous scholarship and in helping to drive robust socially-engaged practice. This article therefore takes the form of a critical review of the politics of knowledge in the area of food studies and security. It explores trends in global food studies research and food security practice, focusing on their relevance and application to the Global South in general, and South Africa in particular. It also turns to case studies and examples of food security practices to anchor the more general survey-based reflection of scholar- ship and policy research. My focus is on the Western Cape - the area in which I work and that I know best. As discussed in a subsequent section on methodology, feminist work is invaluably informed by the lived experiences of the researcher-writer, since these both inform and are informed by the situations and subjects that she confronts.

\section{Food security and human security}

The centrality of food security to human security has long been on the agenda of international rights instruments, development practice, academic scholarship and policy research. In their report on global patterns of hunger at the start of the new millennium, Louise Fresco and Wilfried Baudoin argued that '[f]ood and nutrition security, besides being a goal in itself, has much larger implications and has to be seen as a contribution to a much broader goal and concept which is improved human well-being and security'. ${ }^{1}$ Over a decade ago, Simon Maxwell demonstrated the conceptual and theoretical relevance of establishing the human dimensions of hunger alleviation in a path breaking article published in the journal Science Direct. ${ }^{2}$ Yet, in similar ways to human security, exactly what 'food security' means, and what it takes to realise this at the local, national and global levels, are matters for which the answers have generally been flattened and simplified.

This is evident in the rapid consolidation of the food security research and policy industry since the middle of the $20^{\text {th }}$ century: in the context of proliferating technologies and discourses of development, the field of food security policy, research and practice has steadily garnered donor support through government funding, North to South aid, United Nations (UN) mechanisms and foreign policy. Alongside this, numerous technologies, university courses, academic projects, policy experts and interdisciplinary paradigms have been harnessed to address the pressing problem of global hunger and 'food insecurity' for 
the majority of the world's population. A recent Google search of food security institutions yielded 73300 ooo results, with these including non-governmental organisations (NGOs) and non-profit organisations in the Global North and South, summer schools and institutes for training experts and field workers, and a vast body of literaturefocusing on the problems of the 'food insecure'.

There has been mounting specialisation and sectoral consolidation in these burgeoning areas of agro-food and scientific scholarship and practice. For example, several universities in the Global North now offer specialised graduate programmes. These range from the agro-food focus of the Masters' programme at the Royal Agricultural University in Cirencester, United Kingdom (UK) to the multidisciplinary emphasis at the McGill Institute for Global Food Security in Quebec, Canada. At the same time, there has been a corresponding decline of attention to resources, tools and theories for investigating, understanding and changing social, cultural and historical processes that shape human experiences and subjectivities around food production, consumption and distribution. Interestingly, the Royal Agricultural University unambiguously markets its programmes as career-oriented ones that equip graduates to sell themselves as experts who will apply technical and scientific skills, with very little sociological and historical insight into contexts requiring 'food security' interventions: 'This is the ideal course for those looking for a career in production, policy and sustainable development focusing on food or resource consumption in agriculture ....This course is particularly appropriate for more mature students who are re-directing their careers.'3

It is a predictable irony of our current knowledge economy that a field such as food security studies prioritises productivity, immediate results and short-term solutions, often ignoring the over- arching processes (such as environmental degradation, climate change and histories of colonial and neo-colonial appropriation) that led to the world's food crisis existing in the first place. Thus, many within the new field are not familiar with or interested in, for example, the innovative work of the feminist philosopher Nancy Fraser on gender, feminism, social justice and neo-liberalism. 4

The atomising of the food security research industry (and its severing from scholarship that rigorously investigates power, resource distribution and the historical and discursive construction of dominant knowledge systems) raises the need to do more than simply adding food studies dealing with gender to existing food security work; meaningful interventions would involve investigating the social and political circumstances that led to the emergence and hegemony of the current food security studies industry in the first place. It would also entail addressing the political and interpretive limits of research and policy work in this industry.

One of the research and conceptual gaps resulting from not undertaking this investigation is the absence of work on comprehending and addressing the impact of neo-liberal practice and rhetoric in watering down work that appears to be transformative. And it is noteworthy 
that neo-liberalism has permeated gendered approaches both to food security and to human security. At the outset, then, a review of how ambiguously gender-related work has responded to mainstream security studies research is necessary. The relationship between mainstream and gendered approaches to food security is very similar to the relationships between gender-blind and gendered approaches to food security: on the one hand, work on gender has invaluably complemented gender-blind discussions of food; on the other, certain traditions of work on gender can easily buttress and assimilate the intentions and thrust of mainstream approaches. Elsewhere, I have described the impact and form of this buttressing and assimilation in South African gender policymaking and planning, arguing that:

"The technicist and instrumentalist approach to gender mainstreaming, achieved by using formulaic skills to establish gender disaggregated data which leads to clearly quantifiable 'outputs' is indebted to the Harvard model-type approach that has come to play a major role in supporting neo-liberal development in third-world contexts ... South Africa's gender legislation and policies ... are certainly not mere evidence of patriarchal and elite manipulation. But what does warrant attention is the way a technology of development has come to serve as an overarching framework for thinking about gender in South Africa. This framework, rather than dealing with complex and multi-layered ... social processes, tends to reduce human beings to functional cyphers requiring efficient integration into the modernising and developmental process.” 5

As indicated above, neo-liberalism has had an overarching impact on the language in gendered research on development as well as the vision of transformation embedded in this work. Vigilant and thorough investigation of this work is therefore more than an intellectual or archival exercise; it is part of a vital political intervention into the field of security studies.

In the sections that follow, I tease out various dimensions of this intervention. I explore some of the central concerns within critical work on food and gender politics, drawing particular attention to how these concerns signal the human dimensions of food security and, in substantive ways, establish links between food security and human security. These concerns have been identified by scholars in fields that include cultural studies, critical streams within development studies and interdisciplinary humanities scholarship incorporating history, social geography and gender studies. Much of this work has not, however, been consolidated as a distinct field; nor has its epistemological import been clearly identified vis-à-vis existing regimes of knowledge about food, social justice, and individuals' and groups' security and well-being. The primary aim of this article is to address these overarching concerns.

\section{Discursive space-clearing}

As the "primary cognitive lens through which the complexity and prevalence of global hunger is viewed'6, food security can be investigated as a technology of governance 
institutionalised by the UN and, more broadly, the agendas of corporate global capitalism. From this perspective, 'food security' is not a self-evident linguistic term that 'captures' objectively measurable social and human experiences; rather, it actively constitutes our understanding of such experiences. Consequently, in similar ways to phrases such as 'public participation', 'sustainable development', 'gender transformation', and other current terms in neo-liberal 'public good' discourses (and much academic, social policy research), it conjures up a sense of urgency to legitimise the marshal- ling of specialised actions, material resources, vocabularies, skills and institutions to address social problems. At the same time, like these phrases, it is often either lifted out of, or discursively constructed against, particular historical, cultural and epistemological frameworks. In this way it is presented as a neutral and self-evident area of social intervention that requires urgent and focused remedies.

Compelling arguments are usually made for the need for this positivist approach: real problems, the argument goes, need specialised concepts and urgent, focused problemsolving. And anti-positivist analysis of culture, history and discourse/text in the face of the urgent problems they claim to lay bare is deemed to be gratuitous, self-indulgent or socially irrelevant - hence the proliferation of funding for particular market-driven and developmentalist oriented subjects and fields in the Global South. In South Africa, for example, the Western Cape provincial government provides food security grants to 'support only groups from the historically disadvantaged communities who want to start a garden'.7 Government rhetoric further stresses that, 'The Department of Agriculture will give financial assistance to 20 groups each year for the next three years to support the Food Security Drive ... . This programme wants to support especially women and youth groups.' ${ }^{\prime}$

On the one hand, the professed commitment to the food security needs of poor women and young people is - at face value - laudable; on the other hand, the Western Cape provincial government, like the national government, has been notably restrained about the long-term socio-economic needs of communities in South Africa through, for example, health care, service delivery, employment, higher wages for workers, and housing; all these would be central to their food security. The situation in the Western Cape is not dissimilar to that in many other contexts in the Global South, where funding and grants provided by international donors and governments are made available with the professed aim of alleviating food security, although there is very limited attention to the structural causes of that insecurity. To a large extent, then, food security funding and grants act as quick fix panaceas - provided in lieu of substantial financial support for and political commitment to the broad security needs of poor and struggling communities.

As Heidi Hudson has shown, feminist work on social justice and human security can play a significant role in establishing more inclusive bottom-up approaches that are sensitive to 
the structural causes of insecurity. 9 This is because much of the work on gender, feminism and human security seeks to interrupt dominant bodies of knowledge that simplify questions about and answers to what threatens the well-being of gendered, raced and classed social subject human beings at the micro, macro and global levels. In so doing, it raises epistemological ideas about whose knowledge matters, the perspectives from which knowledge about human security is produced, and how certain voices may be drowned out in canonical and hegemonic perspectives of academic studies, policy research and human rights discourse. Hudson writes:

"Machismo, heralded by the post-9/11 global war against terror, threatens to drown out the progress made during the 1990 os with regard to building a global normative consensus on the importance of human security. Today, more than ever, human security coexists uneasily with national security. Since the analytical potential of feminist epistemology cannot be divorced from its political and transformative value, a critical feminist perspective on the study of security, and especially human security, is crucial to overcome certain gender silences. ... feminism refers to the area where theory and practice meet with regard to transforming the unequal power relationships between women and men. It is more than an intellectual enterprise for the creation of knowledge. It also draws on the struggles of the women's movement and the theorizing emanating from those experiences."10

Similar interruptions, which squarely foreground gender or take feminism into account, have characterised the fields of food security and sovereignty. Within the broad field of gender and food security, research varies theoretically, and scholars have come up with wide-ranging recommendations. These include addressing government policies and development practice, ${ }^{11}$ instituting women's small-scale and community-driven empowerment projects and critiquing multiple power dynamics in explaining how and why particular gendered groups bear the worst brunt of food inequalities. ${ }^{12}$ It is noteworthy that these interpretations focus mainly on how and why certain groups are marginalised or victimised. The consequence of this is an emphasis on how to assist, develop or support subordinated groups, especially women, with tools, resources and expertise external to their own local knowledge economies, food technologies and food systems.

At the margins of this research on gender and food are feminist studies of food sovereignty, which seek to do much more than identify the victims of food inequalities. Exploring food sovereignty, whether in practice or through research, has meant addressing relations of power and control around rights to food, the role of markets and governments, corporate agriculture and Big Food oligarchies. The Food Sovereignty Campaign in South Africa is an important example. As a new alliance, the campaign is committed to forging solidarity among organisations that deal with landlessness, 
exploitation and injustice. During its assembly at the start of 2015, several organisations representing the hungry, the landless and the exploited pledged themselves to concerted action to transform existing food systems and their origins in injustice and exploitation. The campaign's declaration is unequivocal about a holistic approach to social justice and transformation:

"We came together at the Assembly through our shared understanding that we have a crisis- ridden corporate and globalised food system that is responsible for worsening social, health and climate challenges, and which is coinciding with increasing state failure in relation to regulating our food regime and ensuring much needed agrarian transformation. Such a struggle- driven national Food Sovereignty Campaign is unprecedented in the context of South Africa and has drawn inspiration from local food sovereignty practices and from the rising international movements and alliances championing food sovereignty in different parts of the world ... . We are not simply calling for technical solutions for households to access food as encapsulated in the government's recently proposed Food Security and Nutrition Policy and Implementation Plan. We reject the latter and instead are calling for the deep transformation of our food system by breaking the control of food corporations, repositioning the state to realise the Constitutional right to food and as part of creating the conditions and space for the emergence of food sovereignty alternatives from below."13

This attention to struggles related to power relations shifts the focus away from ideas about increased food production or availability that often characterises food security research and interventions. Explaining this by invoking La Via Campesina, who pioneered the concept of food sovereignty, Raj Patel writes:

"Just like the definition of food security, food sovereignty is an evolving and multi-faceted term, but it has an invariant core: 'communities have the right to define their own food and agriculture policy'. To be clear, sovereignty is not a call for self-sufficiency, for states to grow within their borders sufficient food to feed their citizens. La Via Campesina instead calls for people to be sovereign over their food systems, for people to have the power to decide what the system should look like. This is an intentionally vague call, with many questions left open-ended, so that the communities involved in claiming food sovereignty might answer issues around production, distribution, and consumption of food for themselves."

In particular, food sovereignty research focuses on marginalised groups' active struggles and agencies in resisting hunger, rising food crises, food marketing monopolies and the like.

Illustrating how feminism questions consensual ideas about objective or neutral knowledge, this work demonstrates that particular bodies of knowledge in academia, policy research, development practice and the public domain acquire a sense of neutrality and 
authority because of their hegemony. It is therefore unsurprising that gender and food security work has marshalled considerable support from governments, international donors and Northern governments. Feminist scholarship on food encourages us to think about how much of our commonsensical and positivist information and knowledge about food, hunger and hunger alleviation are discursively constituted.

While feminist constructionists are of course not the only scholars who do this, feminist attention to standpoint epistemologies has alerted us to how the givens of our world are defined by the vantage points of those who do the defining. ${ }^{15}$ Given the authority of positivist food security dis- courses, industries and technologies, feminist deconstructions offer tools, theoretical frameworks, methodologies and epistemological critiques for a kind of discursive space clearing around how we talk about food. It can allow us to take a step back away from many positivist and straightforward assumptions about food resources, hunger and power, and develop what Patel describes as a 'heuristic approach to power' and 'a means not only to interpret the system, but also to change it.'16

\section{Indigenous knowledge systems and voices from Below}

One consequence of this discursive space clearing is to create space for voices that are usually drowned out by research and policy experts on global food crises. These marginalised perspectives have often been described in terms of the category of 'indigenous knowledge systems' (IKS) - but it is worth reflecting critically on how these systems have been yoked to dominant food discourses that shut down on much more than they open up. It has been noted by several researchers that IKS within the global knowledge economy are important areas of intervention, since they embed the values, visions and strategies that groups have developed over several generations. ${ }^{17}$ Such knowledge systems therefore disrupt the hegemony of capitalist, state-driven, elite and often patriarchal knowledge, all of which enjoy tremendous authority as 'expertise' or 'science' in the face of 'tradition'. The attention to IKS in sub-Saharan Africa has been particularly significant, and is often defined as a valuable source for energising developmental processes in society that are not driven from above. Interestingly, a World Bank definition of IKS in sub-Saharan Africa notes that:

"Indigenous knowledge is part of the lives of the rural poor; their livelihood depends almost entirely on specific skills and knowledge essential for their survival. Accordingly, for the development process, indigenous knowledge is of particular relevance for the following sectors and strategies: agriculture; animal husbandry and ethnic veterinary medicine; use and management of natural resources." 18

One problem with the field of IKS is the tendency to dwell on rural contexts and agriculture as though these are the only terrains in which alternative marginalised voices talk back to dominant food distribution, sale and growth patterns. Much of the work on IKS, food and 
gender focuses on African rural women subsistence farmers and their indigenous agricultural knowledge. The aim is therefore to mainstream this knowledge or ensure that it is taken into account in policymaking and agricultural planning - and the implicit assumption is that alternatives can come only through what is authentically rural and agricultural. While agriculture and rural contexts are important, the emphasis on these contexts and neglect of others is disturbing. IKS is therefore seen as being in danger of becoming extinct, with the challenge of 'salvaging' threatened knowledge becoming a priority.

As several scholars have shown, Southern Africa - as is the case with many other parts of Africa - is characterised by rapid urbanisation, with many of the squatter camps, informal settlements and townships mushrooming as immigrants from rural areas and beyond the borders of individual countries settle in and beyond city centres. ${ }^{19}$ The especially swift growth of peri-urban areas is testimony to the hybridisation of geographical spaces, subjectivities and lifestyles, with poor, unemployed people being unable to 'live off the land' and remaining wholly dependent on supermarkets, small traders and corner shops for their food needs. The notion of 'indigenous' knowledge systems does not quite do justice to the hybridised, inventive and extremely dynamic negotiations that certain subjects perform in empowering themselves vis-à-vis global food corporations, rising food prices, Big Food operations and rampant liberal economics that absolve governments of responsibility for their citizens' food needs. Moreover, the belief that individuals in these circumstances experience uniform victimisation is a gross simplification of poor consumers' agencies and resources for resistance. For example, work in the informal food sale sector shows that many are able to sell and buy food at reduced prices or on credit, and this makes them less vulnerable to Big Food and the high food prices of supermarkets and fast food chains.

IKS studies on food also suffer from a tendency to see indigenous knowledge as sealed off domains that exist in isolation from modernity and external imperialist-capitalist influence. More useful than this reductive way of thinking about embattled indigenous knowledge is to explore knowledge-making about food consumption, distribution and growth as dynamic, even though marginalised, subaltern and gendered. In other words, these peripheral traditions of knowing can be thought about as oppositional and dynamic bodies of knowledge that contest changing local patriarchal authorities, elitedriven economic policies and practices, and global commodity capitalism. Exploring and analysing local bodies of knowledge, especially those developed by women, would allow us to understand the complex livelihoods and food acquisition strategies that certain groups and individuals develop - despite their apparent entrapment in deprivation and poverty. As some of the work on IKS has shown, it would also counter the top-down emphasis in the specialist field of food security. For example, taking into account what particular groups know about nutrition and well-being in relation to certain plants and foodstuffs means engaging with long-established understandings of how human beings have confronted their local environment, and available routes for obtaining and producing nourishing food. 
Equally importantly, it would consider the central role of food in systems of organisation and rituals where central, often pivotal social values are celebrated, confirmed and defended. A valuable insight into this is Anna Madoeuf's study of feasts in Cairo, Egypt. Madoeuf describes the vibrancy and richness of the moulid as a central food event that combines religious celebration, carnival and feasting among Cairo's city dwellers. Especially notable is the writer's attention to how this food event cements relationships, in particular urban spaces, thus involving Egyptians' encounters with food in ways that far exceed the simple processes of consumption and nutrition. Madoeuf therefore demonstrates that food studies should be integral to understanding the complex ways in which human beings establish relationships to and through food. ${ }^{20}$

Exploring the South African context, and the Western Cape in particular, Gabeba Baderoon draws similar conclusions in her study of food and cooking among Muslims. On the one hand, she critically analyses the way Muslim people's cuisine has been 'exoticised' as 'Malay' cooking through discursive practices that erase Muslims' actual experiences of food and confirm racist constructs of the benign, exotic and tractable 'Cape Malay'. On the other hand, Baderoon shows how Muslim women who began writing and publishing their own cookbooks interrupted traditions of exoticised 'Malay' food cultures. Muslim women who wrote their own cookbooks therefore testified not only to their own knowledge of particular recipes, but also to the rich, complex subjectivities and cultural processes associated with particular food events and recipes. $^{21}$

Apart from the insight provided into certain groups' own knowledge of food, national cuisine and nutrition, understanding local bodies of knowledge about food would provide crucial avenues into understanding food flows as sites of resistance and socially marginalised groups' agencies. Many marginalised and exploited women have devised inventive ways of resisting exploitative food chains and procured, produced or prepared cost-effective and nutritious foods for themselves and others. Examining how organisations or even small support groups negotiate women's empowerment in relation to rising food process and market monopolies is crucial to any feminist effort to explore food sovereignty, and to correct the emphasis on victimisation in much food security studies. The Western Cape's significant tradition of these organisations in the form of the Surplus People Project and Women on Farms could stimulate important work by feminists who engage carefully with and listen to the voices of local women who are forging their own solutions and survival strategies in the face of food insecurity.

A valuable example of an organisation that has addressed not only groups' bottomup approaches to food security but also the complex psychological and emotional repercussions of food struggles is the Gender Equity Unit at the University of the Western Cape. Having emerged in the wake of efforts to pursue gender and other forms of justice on campus during the early 1990s, the unit has run a food programme for hungry students on campus for several years. Unlike welfarist food donation projects, 
however, this unit tries to connect the eradication of hunger to the acquisition of dignity and the instilling of a collective consciousness of injustice and responsibility. The aim of the project is therefore to build awareness around attitudes towards hunger and poverty rather than simply position hungry students as being in need of rescue. The objective is to encourage a sense of collective accountability among the entire campus community, rather than to single out 'hungry students' as a problem to be mechanically fixed and as the object of others' 'generosity'.

This programme has always seemed to me an extremely politically valuable one, not only because of its attention to power but also because of its nuanced attention to the cultural and psychological meanings of hunger and poverty. In illustrating a food sovereignty approach, the project foregrounds the social and psychological dimensions of hunger and poverty as dimensions that are often rendered invisible in many conventional food security approaches. Amartya Sen has been influential in encouraging us to link poverty to 'shame', and therefore understand fully what hunger means to people as human beings. ${ }^{22}$ In distinguishing between capabilities and functioning, he argues that the facilities enabling human beings to realise their capabilities are shaped by cultural factors and access to resources. ${ }^{23}$ In the same way that Sen identified 'the ability to go about without shame' as a capability at the 'irreducible absolutist core in the idea of poverty', shame can also be linked to hunger, generating syndromes of helplessness and inadequacy around the inability to provide or participate. ${ }^{24}$

The more pragmatic approaches to food insecurity neglect these complex factors, ignoring ways in which the perceptions, voices and feelings of marginalised groups are pivotal to strategies for their empowerment and security as human beings. Using a feminist standpoint approach to take into account marginalised voices and bodies of knowledge would therefore mean not only under- standing the ways in which subordinated subjects actively respond to challenges, or develop their own strategies for growing, procuring or distributing food; it would also mean understanding their feelings about what it means to be hungry and, therefore, what measures - whether local or broader - best succeed in their struggles for full empowerment.

The advocacy and critical literacy work pursued by the Gender Equity Unit shows a deep understanding of how hunger affects embodied and culturally-determined subjects, and how the eradication of hunger needs to be connected to understanding its cultural, emotional and psychological dimensions. Such practical work therefore embeds valuable knowledge-making. An emphasis on behavioural responses to food could go a long way towards understanding the intricacies of food consumption and distribution among both the 'stuffed and the starved', as Patel puts it, instead of the usual fixation only on the starving, as though food crises today are simply a matter of making sure that the 
hungry are fed, and not the fact that the current global capitalist monopolising, sale and marketing of food creates a food crisis for us all. 25

\section{Intersectionality, interdisciplinarity and food Studies}

Work on gender is sometimes understood to entail the identification and analysis of gender (and sometimes even of women) as a neatly identifiable unit of study that can be factored into or exist alongside traditional work that ignores gendered relations and powers. But central to feminist intellectual and political work since the late 1900 s is the understanding that gender is always related to other social identities. Thus, intersectionality (the entanglement of multiple identities in every- day struggles and broad global processes) or, in more recent theorising, 'assemblage', has become the focus of inquiry of current feminist work.

Taking intersectionality into account also means fully embracing interdisciplinarity. One of the disturbing features of certain food security studies is that they are locked into highly sectoralised zones of expert knowledge. As the preceding discussion of aspects of applied research as well as sites of graduate study at universities indicates, the recent industry of food security studies has spawned several domains of expert knowledge, often driven by the North, by elites and by scholars who work in tandem with the agendas, and even the directives, of governments and donors. These domains are often marked by blunt quantitative methods and positivist approaches that manage more than they explain. A revealing example is a study of food insecurity in Limpopo, one of the poorest provinces in South Africa, undertaken by a consortium comprising the universities of Stellenbosch, Pretoria, Ghent and Antwerp, and the South African government's Department of Agriculture. The report growing out of this project is revealing about blunt positivistic methods used to generate mainly quantitative data about salient problems, such as how women and children are most affected by food scarcity in poor rural communities. ${ }^{26}$

The report is also indicative of the way in which tremendous resources and efforts are invested in generating statistics through, for example, the administering of questionnaires or organisation of focus groups, methodologies that often limit researchers' insights into how their respondents complicatedly engage with food crises. Lastly, the project and report are revealing about particular alliances and collaborations among academic and state sources that generate flows of funding, knowledge-making and cooperation for experts and elites, while the poor and starving remain objects or beneficiaries of expert knowledge.

In contrast to such studies, the kind of interdisciplinary research that feminists have always undertaken draws eclectically on various disciplines to transcend this arrogant production of knowledge in silos. A fairly recent example of this work is a special issue of the journal Feminist Africa, 'Land, labour and gendered livelihoods', which seeks to draw together the usually separated areas of land, labour and livelihoods. ${ }^{27}$ Focusing on ways in 
which cross-disciplinarity can sharpen theoretical and conceptual frameworks for dealing with the micro and macro levels, contributions carefully engage with gendered, domestic, communal and national levels, showing how access to and control over land and resources is vitally connected to patterns of formal, informal and invisibilised labour, as well as to the ways in which particular groups and social subjects secure and struggle for livelihoods.

As contributions to this special issue reveal, one of the many consequences of embracing intersectionality is to recognise food as a site of struggle and so contribute to expanding theorists' attention to food sovereignty, rather than to food security. Carolyn Sachs' 'Feminist food sovereignty: crafting a new vision' shows that recent interdisciplinary feminist food studies confront - at the local and wider levels - constant struggles over the control and access to resources and around the representation and ascription of identities. ${ }^{28}$ Such struggles are multifaceted and include certain middle-class food consumers' efforts to eat well, women farmers' resistance to corporate monopolisation, individual or collective efforts to control the representation and definition of 'eating well', individuals' gendered resistance to food in the form of anorexia or bulimia, and individual or group representations of 'good food', 'cooking' and cuisine in struggles for individual prestige or cultural or social autonomy. Such social, individual and creative struggles should be crucial to an analysis that avoids stereotyping 'victims' in current food systems. These also connect communal and regional struggles over hunger to broader struggles and systems of meaning making.

Interdisciplinary work on gender and food encourages us to make connections between the materialities of food and discourses around food and eating. Exploring the human dimensions of social, economic and political processes around food therefore offers a place for cultural studies approaches. These can uncover connections between the social and political practices around food and ideologies of food and eating. In their discussion of 'visceral politics', the authors of the journal article 'Taking back taste: feminism, food and the visceral politics' illustrate the value of these humanities approaches by considering how social subjects' beliefs are linked to their every- day experiences of food. ${ }^{29}$ Drawing on post-structural feminism, they unravel plays of power in and around food, tracing power through the body in order to understand the making of the political (eating) subject. Such understanding is not done in the interests of theoretical or analytical dexterity; rather, analysing beliefs, representation and meanings associated with food, eating and the body is crucial to the ability of food-based movements to inspire action across difference and achieve their progressive goals.' 30

Overall then, interdisciplinary feminist approaches to food amplify understandings of power, resistance and freedoms in particular contexts. While the pressing problems of hunger and deprivation have understandably led to a fixation with those who are obviously starving, both hunger and overeating are - as Patel cogently observes - 
symptoms of a single system. ${ }^{31}$ Who eats or over- eats and the conditions under which they eat, as well as who is deprived and what social criteria we use to measure this deprivation, warrant scrutiny not only of obviously visible power relations but also of hidden influences. Such coercive influences could be manifested in anorexia and excessive dieting or obesity as a result of fast food consumption among the poor in developed countries. Encompassing mass media texts, advertising and even so-called scientific and public health mess- ages, these influences echo dominant discourses of gender, class, imperialism and capitalism in local and global social imaginaries.

It is worth stressing how important humanities work is to this interdisciplinary work on food. Among others, Stephen Arnold has dealt critically with the marginalisation of the humanities in development studies, describing it as the brittle nature of development studies, in which 'humans are treated as cyphers and problems become abstractions requiring technical solutions'. ${ }^{2}$ Fiction is often an extremely valuable source of knowledge about the politics of food and hunger; in fact, in similar ways to many feminist studies, fiction frequently explores the cultural and metaphoric complexities and cultural relativity of 'hunger', food and eating. In Anita Desai's novel, Fasting, feasting, the dislocation and alienation of an Indian immigrant in the United States (US) is explored in relation to his struggles to eat well (on his terms), while the daughter of the American family with whom he lives overeats compulsively as she experiences her own painful sense of alienation and body dysmorphic disorder in a world obsessed with conspicuous consumption alongside obsessions around body image. 33 The novel intricately unravels the contradictory and multiple layers of distress, discomfort and deprivation associated with food consumption and acquisition in North-South dynamics, exploring ways in which class, region, gender and race are intricately webbed in the meanings attached to and the circuits of food. As a work of fiction, Desai's insight is distinctive in dwelling on character and consciousness in ways which scholarship simply cannot. At the same time, it is worth stressing that much feminist work, because of its efforts to challenge linear and masculinist content and forms of knowledge, is acutely alert to the kinds of intersections around power that Desai's novel explores.

\section{Methodological innovations}

Attentiveness to indigenous and marginalised bodies of food knowledge is connected to a crucial area for feminist interventions into food and human security studies; namely, the value of policy or scholarly research that effectively identifies and 'hears' knowledge-making beyond academia - i.e., knowledge-making among marginal groups. Much feminist research has been path-breaking in developing methodological approaches that unsettle conventional researcher-researched relations and therefore uncover more expansive sources and forms of knowledge. Some of the most democratising methodological work in the social sciences and humanities has emanated from feminist research and teaching on gender. Such work has entailed, for example, the use of personal narrative; participatory action research; genre-blending in research products through incorporating life narratives 
into scholarship or policy research; and using visual methodologies that encourage a richer and more polysemous analysis than is often the case with written text.

An important example of one such study is Goolam Vahed and Thembisa Waetjen's social history, which uses cookbooks, cultural activities, social circles and networks organised by women in Durban to provide a textured history from below, along with theoretically-focused insight into matters of race, class, caste and gender that are often erased in more orthodox historical studies. 34 It is noteworthy that sections of the study that deal with women's preparation of food, their collection of recipes, the social networks they formed around food rituals, and their authority in feasts and meals within their families and communities are the richest entry points in the authors' analysis of the manylayered private and social experiences of their subjects.

But most importantly, much feminist research is deeply committed to researchers' autoreflexivity as a guiding principle for ensuring the researcher's humility in the face of her subject matter and research participants. In other words, encouraging the researcher to position herself, her own investment in her work, and her inevitably blinkered ways of knowing, in all stages of the research process. It is sometimes striking how often the charge of 'bias' or 'lack of scientific rigour' creeps into the arguments of scholars and students of human security and food security. The assumption is that perspective and standpoint can somehow be eliminated, as though they are faults to be over- come with 'properly scientific measures in other words, the belief that the aim of research is to arrive at universal truths.

As feminists have long shown, claims of scientific rigour or universality are often invoked to mask (inevitably) positioned ways of understanding and knowing. The more challenging task of research is to make transparent these positioned ways of knowing and so uncover more inclusive bodies of knowledge and conversations around these. Feminists who have adopted standpoint epistemologies have therefore argued that it is often through the perspectives of women and other socially subordinate groups that far richer and more productive insights into power relations have emerged. Among these, Patricia Hill Collins and Sandra Harding have provided central responses. As a feminist philosopher of science, Harding contests the naturalised claim to universality in dominant knowledge-making by arguing that, paradoxically, richer political and theoretical ideas are likely to be provided by those at the margins. She writes: 'Starting off research from women's lives will generate less partial and less distorted accounts not only of women's lives but also of men's lives and of the whole social order.'35 Echoing this in her discussion of black feminist standpoint, Hill Collins insists that black women, like other multiply marginalised groups, are able to develop epistemologies on the basis of their vantage points. These gesture towards universal insights into the 'human', understandings of power and the locations of dominant groups from the perspective of 'seeing from below'. 36 
As discussed above, the field of food security, including the small but growing field of gender and food security, has been marked by rigid and top-down research methods. Often defined as incontrovertible 'science', these can seriously distort and neglect understandings not only of poor and socially marginalised people's experiences of food; they can also distort understanding of the wider food systems in which particular experiences of hunger and powerlessness exist.

One especially promising feminist intervention would involve methodologies linked to the use of visual texts. Several methodologies for using visual texts in mainstream food security studies are already being utilised in food security studies. One participatory action research method, frequently used for developmental projects in South African contexts, is photovoice. As a bottom-up methodology, photovoice uses the registers, images and perspectives of research participants to develop knowledge about particular subjects, and so refuses the idea of research subjects being passive repositories of information. As one study indicates, photovoice can yield important insights into ways in which groups living with HIV/AIDS experience and respond to contextually-specific food and nutritional imperatives, given specific economic, health and health-care constraints. 37 Their work therefore demonstrates how photovoice can support qualitative studies for producing a rich analysis of nutritional security and health, and for providing valuable information in critical public health programmes.

Yet there is much more that visual texts can unravel about food, food cultures and human subjectivities from a feminist perspective. Here I would like to outline some avenues offered by feminist documentary filmmaking, and, in particular, the work of the Cape Town-based film-maker Shelley Barry. Interestingly, Barry's films are not primarily about food; nor do they foreground food as a central theme in the way that they centralise the struggles for dignity of disabled people in mainstream society, or lesbian agencies and black women's experiences. Yet food repeatedly surfaces as a language in Barry's films, providing tropes, images and filters through which the filmmaker explores a host of stories about belonging, sexuality, fulfilment and freedom.

This is especially pronounced in her documentary on the activist writer, Charlene Maslamoney, who died in 2013 after battling cancer for several years. Im Not Done Yet (2014) tells a powerful story about Maslamoney's efforts to heal herself and to help others heal themselves from nutritional, political and spiritual points of view. $3^{8}$ The story of her final years is interwoven with her encounters and experiments with good food and healthy eating. As an activist, Maslamoney criticises the exorbitant prices of health foods but also confirms the value of eating well, learning to understand the value of certain foods, spices and herbsas well asthe desirability of women with limited finan- cial resources doing so. In view of the widespread tendency in public health discourses to pathologise black women as health risks because of their ignorance, 39 the film is a powerful black feminist response that testifies to black women's knowledge and understanding of food. The documentary is a powerful counter to dominant public health didacticism, and the viewer is able to learn crucial lessons about 
healthy eating by empathetically engaging with the intensely personalised journey of the protagonist as she playfully talks about her spiritual, health and political struggles. It is a film that has clear practical relevance in South Africa, where diseases linked to nutritional security, such as TB, cancer and HIV/AIDS, place many women under particular pressure to eat well in the face of limited economic resources, support networks or health care services. At the same time, it is not a film that dogmatically instructs viewers; rather, it is a form of knowledgemaking through visual storytelling that allows the viewer to actively engage with the lessons traced in the protagonist's story. There is considerable scope for developing the small tradition of feminist as opposed to gender- sensitive research methodologies that actively work with, rather than for, subordinate groups. As LisaWeasel putsitin her study of India:

"Research in the natural sciences has tended to focus uncritically on technoscientific solutions to the problem of global food security. Yet the intended recipients ... often lower-caste women, have in some cases been vehement opponents of these solutions. Qualitative participatory approaches informed by feminist principles, can elucidate the reasons for this rejection and help to chart a more appropriate epistemological orientation for developing solutions based in communitymembers' lives and needs." 40

\section{Conclusion}

In Charles Dickens' famous novel, Oliver Twist, the central character pleads: 'Please sir, I want some more.' Set in Victorian England, where capitalist production has begun to entrench divides between the controllers of food resources and the producers who have limited control over these, the novel powerfully illustrates the plight of the 'food insecure'. It also captures the remark- able complacency of the dominant classes. $\mathrm{Mr}$ Bumble's outraged response to Oliver's request for more food vividly reveals the refusal of those in positions of relative power to acknowledge the plight of the starving majority. It also powerfully reveals the elite's refusal to hear the masses' voices. In our current context of global capitalist production, the refusal to 'see' starvation or the voices of the hungry seems to be replicated in responses ranging from denial to quick-fix efforts to alleviate deeply embedded economic, political and social circumstances. Unless our responses seek to address these multifaceted circumstances, they will continue to remain part of the problem, rather than a means toward discovering solutions.

\section{Acknowledgements}

I am indebted to the Mellon Foundation for funding the project of which my research is part: "Food Politics and Cultures: Humanities Approaches to Food and Food Systems". Begun in June 1015, this project is housed in the Women's and Gender Studies Department at the University of the Western Cape, and is located within the Centre of Excellence on Food Security at UWC. 


\section{Notes}

1. LA Fresco and W Baudoin, Food and nutrition security towards human security, 2007 www.fao.org/ag/agp/agpc/doc/ reports/icv02egospe.pdf(accessed August 2015), 15.

2. S Maxwell, Food security: a post-modern perspective, Science Direct, 21, 1996. Royal Agricultural University, MSc Sustainable Agriculture and Food Security, www.rau.ac.uk/study/postgraduate- study/sustainable-agriculture-and-food-security/sustainableagriculture-and-food-security-msc.

3. NFraser, Feminism, capitalism and the cunning of history, New Left Review, 56, March/April 2009.

4. D Lewis, The politics of 'do-ing gender' in South Africa: implications for social work, Social Worker Practitioner- Researcher, 24, 2012, 16.

5. RAlcock, Speaking food: a discourse analytic study of food security, 2009, www.bristol.ac.uk/medialibrary/sites/spais/ migrated/documents/alcock0709.pdf(accessed July 2015)

6. Western Cape Government, Funding and Support, www.westerncape.gov.za

7. Ibid.

8. H Hudson, A feminist perspective on human security in Africa, in H Solomon \& M van Aardt (eds.), 'Caring' security in Africa, Pretoria: Institute for Security Studies, 1998.

9. H Hudson, 'Doing' security as though humans matter: a feminist perspective on gender and the politics of human security, Security Dialogue, 36, 2005, 155-156.

10. See M de Klerk et al, Food security in South Africa: key policy issues for the medium term, 2004, http://sarpn.org/ documents/do000685/Food_security_SA_January2004.pdf(accessedJuly 2015).

11. Institute of Development Studies, Gender and food security: towards gender - just food and nutrition security, 2014,

http://opendocs.ids.ac.uk/opendocs/bitstream/handle/123456789/5245/IDS_Bridge_Food_Security_Repor t_Online. pdf?sequence=3 (accessed July 2015).

12. Food Sovereignty Campaign Coordination Committee, Declaration of the South African Food Sovereignty Campaign and Alliance, 2015, www.copac.org.za/files/Food\%20Sovereignty\%20Assembly\%20Declaration.pdf (accessed August 2015), 1.

13. RPatel, Food sovereignty: power, gender, and the righttofood, PLoS Med 9(6): e1001223, 1.

14. S Harding, Rethinking Standpoint Epistemology: What is Strong Objectivity?, in L Alcoff \& E Potter (eds.), Feminist Epistemologies, New York/London: Routledge, 1993.

15. RPatel, Food sovereignty: power, gender, and the right to food, PLoS Med 9(6): e1001223.

16. PBates et al(eds.), Learning and knowing in indigenous societies today, Paris: UNESCO, $2009,3$. 17.World Bank, Regions: sub-Saharan Africa, www.worldbank.org/afr/ik/basic.htm (accessed August 2015).

18.A Simone \& A Abouhani (eds.), Urban Africa: changing contours of survival in the city, Dakar:

Codesria Books, 2005.

19. A Madoeuf, Feasts: panoramas in town - the spaces and times of the moulids of Cairo, Pretoria: Codesria, 2005.

20. GBaderoon, Regarding Muslims, Johannesburg: Wits University Press, 2014.

21. A Sen, Commodities and capabilities, Oxford: Oxford University Press, 1985.

22. A Sen, Poor, relatively speaking, Oxford Economic Papers, 35, 1983.

23. Ibid., 165 .

24. R Patel, Food sovereignty: power, gender, and the right to food, PLoS Med 9(6): e10012

25. National Agricultural Marketing Council, Food security vulnerability in South Africa: case study Limpopo, www.namc. co.za/upload/presentation/Presentation\%20food\%20security\%20limpopo\%20final1.pdf (accessed July 2015). 
26. F Liersch (ed.), Land, labour and gendered livelihoods (Feminist Africa, issue 12), 2009.

27. C Sachs, Feminist food sovereignty: crafting a new vision, paper presented at the International Conference on Food Sovereignty: A Critical Dialogue, Yale University, New Haven, 14-15 September 2013.

28. A Hayes-Conroy \& J Hayes-Conroy, Visceral difference, feelings and social boundaries in slow food, in A Hayes (ed.), Bodily geographies of 'slow' food: food activism and visceral politics, Clark University, Worcester, 2009;

29. A Hayes-Conroy \& J Hayes-Conroy, Taking back taste: feminism, food and visceral politics, Gender, Place \& Culture: A Journal of Feminist Geography, 15, 2008, 1.

30. A Hayes-Conroy \& J Hayes-Conroy, Visceral difference, feelings and social boundaries in slow food, in A Hayes (ed.), Bodily geographies of'slow' food: food activism and visceral politics, Clark University, Worcester, 2009.

31. R Patel, Stuffed and starved: the hidden battle for the world food system, New York: Melville House, 2008.

32. SArnold, Preface, in S Arnold \& A Nitecki (eds.), Culture and development in Africa, Trenton: Africa World Press, 1990.

33. A Desai, Fasting, feasting, London: Chatto and Windus, 1999.

34. GVahed \& T Waetjen, Gender, modernity and Indian delights: the women's cultural group of Durban: 1954-2010, Cape Town: HSRC Press, 2010.

35. S Harding, Whose science? Whose knowledge? Thinking from women's lives, New York: Cornell University Press, 1991, 121.

36. PHill Collins, Black feminist thought: knowledge consciousness, and the politics of empowerment, 2nd ed., New York: Routledge, 2000, 251.

37.Swaans, Broerse, Meincke, Mudhara and Bunders (2009). Promoting food security and well-being among poor and HIV/AIDS affected households: lessons from an interactive and integrated approach. Eval Program Plann. 2009 Feb;32(1):31-42. doi: 10.1016/j.evalprogplan.2008.09.002. Epub 2008 Sep 24.

38. SBarry(director), I'm not done yet!,2014.

39. M Malan, SA's the fattest sub-Saharan nation, Mail and Guardian, 29 May 2014.

40. LH Weasel, Conducting research from the ground up, International Review of Qualitative Research, 4, 2011, 417. 